\title{
Optimizing the Quadruple-potential Waveform for the Deter- mination of Gentamicin Sulfate by High Performance Liquid Chromatography with Pulsed Electrochemical Detection
}

\author{
CAI, Ya-Qi(蔡亚岐)ＭOU, Shi-Fen*(牟世芬) \\ State Key Laboratory of Environmental Chemistry and Ecotoxicology, Research Center for Eco-environmental \\ Sciences, Chinese Academy of Sciences, Beijing 100085, China
}

\begin{abstract}
In this paper, a quadruple-potential waveform was investigated and optimized for the determination of gentamicin by reversed phase ion-pair chromatography. Instead of a relatively high positive potential, a negative potential was adopted as a potential for the cleaning of gold working electrode. By this way, the formation of gold oxide resulting from the application of high positive potential during the analyte detection and electrode cleaning was greatly reduced, and therefore, the dissolution and recession of gold working electrode was also reduced. The good condition of gold working electrode achieved by this quadruple-potential waveform can help us to obtain a good reproducibility. In order to acquire signal-to-noise ratio as high as possible, several waveform parameters affecting the detection of gentamicin were carefully selected. The analytical method has been applied to the determination of two real gentamicin samples, and good results with low relative standard deviation not more than $4 \%$ were obtained.
\end{abstract}

Keywords quadruple-potential waveform, pulsed electrochemical detection, reversed phase ion-pair chromatography, gentamicin

\section{Introduction}

Gentamicin is a water soluble aminoglycoside antibiotic used to treat bacterial infections in human being and animals, and has a rather broad spectrum of activity against gram-negative bacteria. Gentamicin consists of four major components $\mathrm{C}_{1}, \mathrm{C}_{1 \mathrm{a}}, \mathrm{C}_{2}, \mathrm{C}_{2 \mathrm{a}}$ and several minor components such as $\mathrm{C}_{2 \mathrm{~b}}$ and other impurities, with their chemical structure shown in Figure 1. A suitable proportion of every component and impurity contents as low as possible are prerequisites for a gentamicin product with a good quality. Thus, simple, sensitive, accurate and reliable methods for the determination of gentamicin products are in great demand in quality control

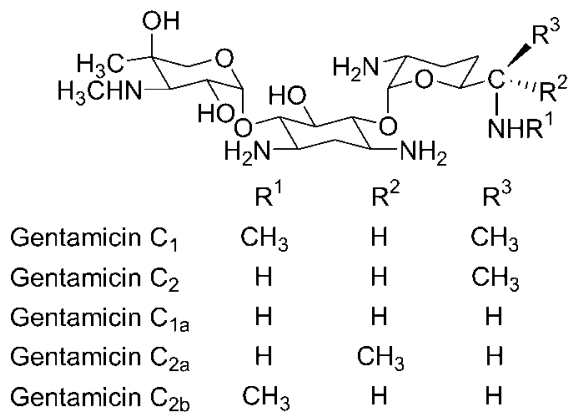

Figure 1 The chemical structure of gentamicin components. and assurance.

The traditional method for determination of gentamicin is nonspecific microbiological assay, which is suffered seriously from the interferences of other co-existing antibiotics, the active metabolites and degradants of gentamicin. Many chromatographic methods such as thin layer chromatography, ${ }^{1-3}$ ion-exchange liquid chromatography, ${ }^{4-6}$ reversed phase liquid chromatography ${ }^{7-20}$ and capillary electrophoresis, ${ }^{21}$ have been also used to determine gentamicin. Because lacking strong UV chromophores in its molecule structure makes direct detection of gentamicin very difficult, most of the methods mentioned above need some suitable derivatisation, which causes these methods to be time-consuming and to lack applicability. However, the hydroxyl and amino groups of its molecule structure present the possibility of detecting gentamicin by electrochemical method as used for the determination of amino acids and carbohydrate. ${ }^{22-33}$ Several papers have been published for the determination of gentamicin by HPLC with pulsed amperometric detection (PAD) ${ }^{4,34}$ In these methods, gentamicin can be separated by HPLC and then oxidized and detected at gold electrodes in a high $\mathrm{pH}$ solution. Indeed, these methods possess high sensitivity and selectivity. However, in the triplepotential waveform used in these methods, a relatively

\footnotetext{
* E-mail: shifenm@mail.rcees.ac.cn; Tel.: 010-62849182

Received September 13, 2004; revised April 15, 2005; accepted May 23, 2005.

Project supported by the Major State Basic Research Development Program (No. 2003CB415001) of China and the National Natural Science Foundation of China (No. 20475060).
} 
high positive potential lasting a quite long period was used to clean the surface fouling of gold electrode from the oxidized analytes, which can maintain the electrode to be clean and catalytically active to analytes. A major drawback of the triple-potential waveform is a slow dissolution and recession of the surface of gold working electrode from an excessive oxidation of gold on the electrode surface during the cleaning step, which makes thin-layer channel thickness increase, and therefore causes a decrease in detection sensitivity and reproducibility. To overcome this disadvantage, Jensen et al. ${ }^{35}$ and Rocklin $e t \mathrm{al}^{22}$ advanced a novel quadruple-potential waveform and applied it successfully to detection of carbohydrates. Clarke et al. $^{23}$ further developed this quadruple-potential waveform to six-potential waveform for the detection of amino acids and amino sugars. In these methods, a high negative potential instead of a high positive potential was adopted to clean the electrode fouling from oxidized analytes. The application of these methods involving a high negative cleaning potential indeed helped to improve freedom from electrode fouling, detection sensitivity and reproducibility. Although great advances have been achieved in the application of quadruple-potential waveform to the determination of carbohydrates, amino acids and amino sugars, up to now, we have not found the published paper concerning the application of quadruple-potential waveform to the determination of aminoglycoside antibiotics. Recently, we have just done some research on the determination of netilmicin using HPLC coupled with quadruple-potential waveform electrochemical detection. The experimental results showed that the method we developed indeed exhibited higher resolution, higher sensitivity and better long-term stability than the HPLC method coupled with triple-potential waveform electrochemical detection. This research work has been published in USP forum. ${ }^{36}$ In this paper, we present a new method using quadruple-potential waveform coupled with HPLC for the determination of gentamicin components and co-existing impurities. The experimental results showed that our method is suitable to analyze the gentamicin drugs and can meet the demand of European Pharmacopeia.

\section{Experimental}

\section{Reagents and samples}

Purified water produced by a compact ultrapure water system (Barnstead, Iowa, USA) was used throughout the experiments. Guarantee grade reagent sodium sulfate anhydrous, sodium hydroxide, $85 \%$ phosphoric acid, potassium dihydrogen phosphate and LC-grade tetrahydrofuran were purchased from Beijing Chemicals Corporation, Beijing, China. Sodium 1-octanesulfonate monohydrate was obtained from Acros Chimica. The buffer solution ( $\mathrm{pH}$ 3.0) was prepared by mixing 0.2 $\mathrm{mol} / \mathrm{L}$ potassium dihydrogen phosphate and $0.2 \mathrm{~mol} / \mathrm{L}$ phosphoric acid. $0.5 \mathrm{~mol} / \mathrm{L}$ sodium hydroxide was made using $50 \%(\mathrm{~m} / \mathrm{m})$ sodium hydroxide aqueous dilution. Gentamicin sulphate CRS as a mixture of $26.5 \% \mathrm{C}_{1}$, $33.1 \% \mathrm{C}_{1 \mathrm{a}}, 26.0 \% \mathrm{C}_{2}$ and $14.6 \% \mathrm{C}_{2 \mathrm{a}}$ was purchased from Pierrel (Capua, Italy). Gentamicin samples were provided by two producers in China.

\section{Apparatus}

All experiments were performed by a DX-600 ion chromatograph (Dionex, USA). The chromatographic system consisted of a GS50 gradient pump, an AS50 autosampler, an AS50 thermal compartment for keeping a column at constant temperature and an ED50 electrochemical detector equipped with a thin-layer type PED amperometric cell. The cell gaskets in our system had the following dimensions (thickness $\times$ fluid channel width $\times$ fluid channel length): $0.140 \mathrm{~mm} \times 3.5 \mathrm{~mm} \times 14$ $\mathrm{mm}$. The cell consisted of a $3.0 \mathrm{~mm}$ gold working electrode, an $\mathrm{Ag} / \mathrm{AgCl}$ reference electrode and a titanium counter electrode existing as the cell body. A personal computer equipped with Peak Net 6.1 software was used to acquire and process chromatographic data. Peak area was used as the analytical measurement.

\section{Chromatographic conditions}

In our experiments, a PLRP-S column $(250 \mathrm{~mm} \times$ $4.6 \mathrm{~mm}$, particle size $8 \mu \mathrm{m}$, porous diameter $100 \mathrm{~nm}$, PS-DVB resin packing, polymer Laboratories, Shropshire, UK) was used as analytical column. For a satisfactory separation and determination, the temperature of AS50 thermal compartment was set at $40{ }^{\circ} \mathrm{C}$ constantly.

The mobile phase consisted of an aqueous solution containing $65 \mathrm{~g} / \mathrm{L}$ anhydrous sodium sulphate, $1.7 \mathrm{~g} / \mathrm{L}$ sodium octanesulphonate, $13 \mathrm{~mL} / \mathrm{L}$ of tetrahydrofuran, $50 \mathrm{~mL} / \mathrm{L}$ of $0.2 \mathrm{~mol} / \mathrm{L}$ potassium dihydrogenphosphate previously adjusted to $\mathrm{pH} 3.0$ with a $0.2 \mathrm{~mol} / \mathrm{L}$ solution of phosphoric acid and was sonicated to degas prior to use. The flow rate of the mobile phase was set at 1.0 $\mathrm{mL} / \mathrm{min}$. All reference and sample solutions to be analyzed were prepared by diluting with the mobile phase. To get better reproducibility and higher detection response, with a nitrogen pressurized reservoir, $0.5 \mathrm{~mol} / \mathrm{L}$ carbonate-free sodium hydroxide solution was added pulse-less to the column effluent using a $375 \mu \mathrm{L}$ polymeric mixing coil at a flow rate of $0.3 \mathrm{~mL} / \mathrm{min}$.

In our experiments, the novel quadruple-potential waveform was selected as detection potential waveform and shown in Figure 2.

\section{Experimental solutions and quantitative method}

The quantitative method of gentamicin sulphate used was established in accordance with the demand of European Pharmacopoeia 4.5 07/2003:0331 method. The experimental solutions were prepared as follows:

Test solution: Dissolve $50.0 \mathrm{mg}$ of gentamicin sulphate drug sample in the mobile phase and dilute to $100.0 \mathrm{~mL}$ with the mobile phase.

Reference solution a: Dissolve $50.0 \mathrm{mg}$ of gentamicin sulphate CRC in the mobile phase and dilute to $100.0 \mathrm{~mL}$ with the mobile phase. This reference solution 


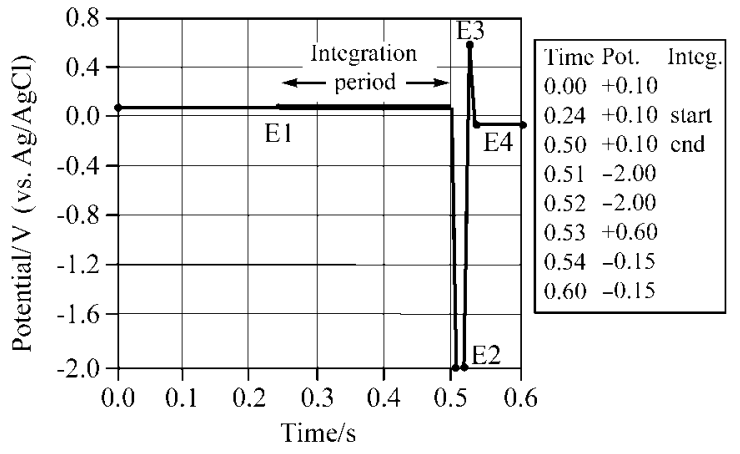

Figure 2 Quadruple-potential waveform for pulsed amperometric detection.

was used to test the system suitability and the peak-tovalley ratio of gentamicin $\mathrm{C}_{2 \mathrm{a}}$ and gentamicin $\mathrm{C}_{2}$.

Reference solution b: Dilute $5.0 \mathrm{~mL}$ of reference solution a to $100.0 \mathrm{~mL}$ with the mobile phase. This reference solution was used to determine disregard limit.

According to European Pharmacopoeia 4.5 07/2003: 0331 method, the response factors for gentamicins $\mathrm{C}_{1 \mathrm{a}}$, $\mathrm{C}_{2}$ and $\mathrm{C}_{2 \mathrm{~b}}$ relative to $\mathrm{C}_{1}$ were all about one. Because the gentamicin $\mathrm{C}_{2 \mathrm{a}}$ is an isomer of gentamicin $\mathrm{C}_{2}$, its response factor can be assumed to be one, then every component relative content can be calculated by normalization.

\section{Results and discussion}

\section{Chromatographic conditions}

The chromatographic conditions in this paper were developed by making some suitable modification to the European Pharmacopoeia 4 01/2002:1351 method. The column temperature $40{ }^{\circ} \mathrm{C}$ adopted is the highest temperature of our instrument, which is lower than that of European Pharmacopoeia 4 01/2002:1351 method (50 $\left.{ }^{\circ} \mathrm{C}\right)$. To maintain approximately the same eluent capacity, a more concentrated tetrahydrofuran, sodium sulphate and a slightly dilute sodium octanesulphonate were adopted. It was found that the retention time of this method was very dependent on the concentration of sodium octanesulphonate and tetrahydrofuran, so the concentrations of these two components had to be controlled strictly, which is a drawback of this method on one hand, but on the other hand, what is a strong point, it can be used to adjust the resolution easily. For example, the concentrations of sodium sulphate, sodium octanesulphonate and $\mathrm{pH} 3.0$ buffer could be fixed at constant to be $65 \mathrm{~g} / \mathrm{L}$ anhydrous sodium sulphate, $1.7 \mathrm{~g} / \mathrm{L}$ sodium octanesulphonate and $50 \mathrm{~mL} / \mathrm{L} \mathrm{pH} 3.0$ buffer, but the concentration of tetrahydrofuran could be changed in the range of $12-13 \mathrm{~mL}$. Experimental results showed that when $13 \mathrm{~mL}$ of tetrahydrofuran were used, one chromatographic process could be completed within a relative short time (37 $\mathrm{min}$ ) with a good resolution (peak-to-valley ratio equal to 3.7) that could meet the demand of European Pharmacopoeia (peak-to-valley ratio greater than 2). But when $12 \mathrm{~mL}$ of tetrahydrofu- ran were used, a better resolution could be obtained (peak-to-valley ratio equal to 4.3) within a slightly longer time (about $45 \mathrm{~min}$ ).

\section{Waveform optimization}

The main goal of this paper is the optimization of quadruple-potential waveform. Each of the four potentials shown in Figure 2 plays a different role. The optimization of every potential is very important to get an excellent analytical performance.

Optimization of detection potential E1: The detection potential E1 is the potential at which the current from the oxidation of gentamicin is integrated. When maintaining the other experimental conditions at constant, the effect of detection potential (E1) on the peak area of five components and the baseline noise was investigated and the results are shown in Figure 3. On one hand, when the detection potential E1 was below $0.15 \mathrm{~V}$, the effect of detection potential E1 on the peak area was relatively obvious, but when the detection potential E1 was above that value, the detection potential E1 nearly had no obvious influence on the peak area. On the other hand, when the detection potential E1 was below $0.15 \mathrm{~V}$, the baseline noise almost remained invariable, but when the detection potential (E1) is above that value, with the increase of the detection potential E1, the baseline noise had a very rapid increase. To get a high signal-to-noise and detection sensitivity, the $0.10 \mathrm{~V}$ was chosen as detection potential E1 in our method.

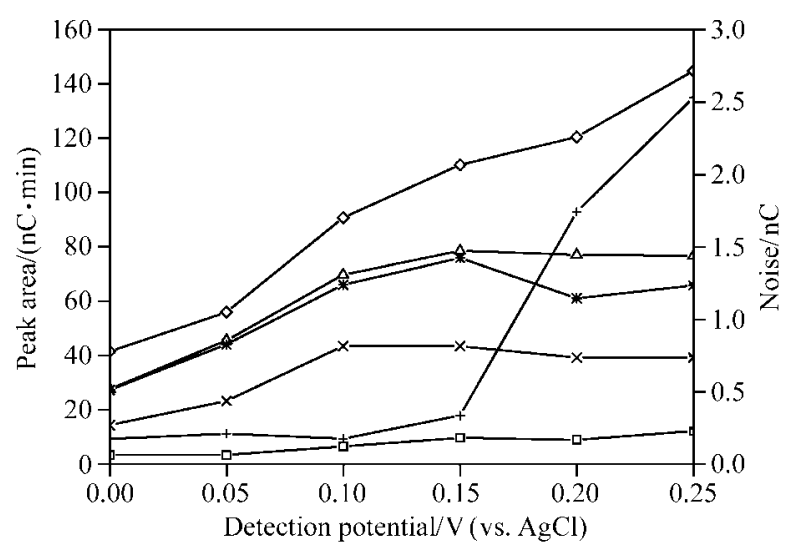

Figure 3 Effect of detection potential on the peak area of five gentamicin components and baseline noise. $\diamond: \mathrm{C}_{1 \mathrm{a}}, \square: \mathrm{C}_{2 \mathrm{~b}}, \triangle$ : $\mathrm{C}_{2}, \quad \times: \mathrm{C}_{2 \mathrm{a}}, *: \mathrm{C}_{1},+$ : baseline noise.

According to the related theory and experiment, peak area is directly proportional to the integrated period, while the baseline noise has also something to do with the integrated period. When the integrated period is in suitable range, it has no effect on the baseline noise, but when the integrated period is too long, it will result in rapid increase in baseline noise. In addition, too long integrated period leads to a decrease in data acquisition rate, a rough chromatogram and a poor reproducibility. Therefore, it was essential to find a compromise among high signal, low noise and suitable length of total 
waveform period. Based on consideration above, 260 $\mathrm{ms}$ were selected as integrated period in our experiment.

Optimization of cleaning potential E2: The most serious problem of electrochemical detection method with fixed-potential conditions is the fouling of electrode from the adsorption of reaction products and other impurities, which can result in very poor reproducibility and serious sensitivity loss. In the triple-potential waveform, to some extent, this problem was overcome with repetitive electrode cleaning by applying a high positive potential for a relatively long time following the detection period. But this measure can cause very serious electrode recession because of the excessive oxidation and dissolution of gold on the electrode surface, which makes thin layer channel thickness increase, and therefore also causes a decrease in detection sensitivity and reproducibility. In the quadruple-potential waveform, a high positive cleaning potential is replaced with a high negative one. According to Rocklin et al. ${ }^{22}$ the possible mechanism of cleaning at negative potential is that the reaction products and other impurities adsorbed on the surface of electrode can be displaced by hydrogen atoms produced from the reduction of water. The effect of cleaning potential E2 on the peak areas of five gentamicin components was examined in the potential range of $-1.2--2.0 \mathrm{~V}$ and the results are shown in Figure 4. From this figure, it could be found that with the decrease of the potential in the range of $-1.2-$ $-1.4 \mathrm{~V}$, the peak areas were increased steadily. But when the potential became more negative, the peak areas nearly remained unchangeable. Furthermore, it was also found that when the potential was in the range above, no obvious change in baseline noise was observed. The electrode cleaning can be improved by adopting a long cleaning duration, but this can cause the increase of baseline noise. Based on such facts, -2.00 $\mathrm{V}$ were selected as cleaning potential E2, $10 \mathrm{~ms}$ as the period of negative cleaning potential duration.

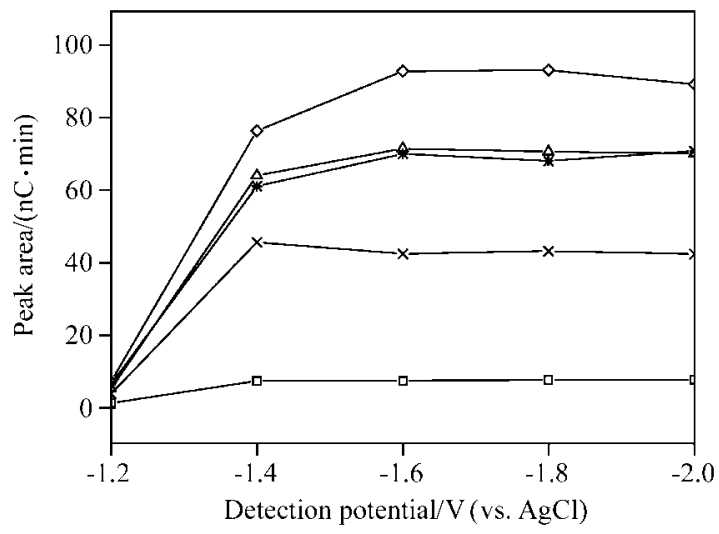

Figure 4 Effect of cleaning potential on the peak area of five gentamicin components. $\diamond: \mathrm{C}_{1 \mathrm{a}}, \square: \mathrm{C}_{2 \mathrm{~b}}, \triangle: \mathrm{C}_{2}, \times: \mathrm{C}_{2 \mathrm{a}}, *: \mathrm{C}_{1}$.

Optimization of activation potential E3 and oxide reduction potential E4: The purposes of the third and fourth potential called activation potential E3 and oxide reduction potential E4 are to maintain an electrode catalytically active. It is thought that the catalytic sites on the surface of the gold electrode are those low coordination gold atoms produced by forming and then reducing surface gold oxide. ${ }^{22,37,38}$ It was reported that omission of this transient oxide step (activation potential E3) resulted in rapidly decrease of peak areas of analytes. Thus, while setting the other experimental parameters at constant, the effect of activation potential (E3) on the peak area of five components and the baseline noise in the potential range of $0-1.0 \mathrm{~V}$ was examined. On one hand, the peak areas of five components did not show great fluctuations at higher levels when the activation potential $\mathrm{E} 3$ was between 0.2 and $0.8 \mathrm{~V}$, and they reached the highest points when the activation potential E3 was at $0.6 \mathrm{~V}$. On the other hand, when the activation potential E3 was between 0.2 and $0.8 \mathrm{~V}$, the baseline noises almost remained constant at relatively lower levels. To get a high signal-to-noise and detection sensitivity, the $0.60 \mathrm{~V}$ was adopted as activation potential E3 in our method. Considering that a quite long duration of activation step resulted in serious electrode recession, therefore, a measure to take was that the activation potential was ramped up to $0.60 \mathrm{~V}$ and then down to $-0.15 \mathrm{~V}$ without any holding.

Following the activation step of gold electrode at positive potential E3, a negative oxide reduction potential E4 had to be applied to the gold electrode to reduce gold oxide formed at the positive activation potential. It is in this circle of formation and then reduction of gold oxide on the surface of electrode that the catalytically active sites on the gold electrode surface are produced. To reduce the gold oxide completely, the potential chosen must be negative, but too negative potential is responsible for the reduction of dissolved oxygen and then the baseline noise dip resulting from the reduction of dissolved oxygen. ${ }^{22}$ The effect of the oxide reduction potential (E4) on the peak area was examined in the potential range of $-0.40-0.0 \mathrm{~V}$. When the potential was in the range of $-0.10--0.20 \mathrm{~V}$, the peak areas of five gentamicin components got to higher levels, and when the potential was around the $-0.15 \mathrm{~V}$, these peak areas reached the highest levels. According to Rocklin's research, ${ }^{22}$ reduction of gold oxide is a relatively rapid process and the duration of oxide reduction potential E4 is not critical. Therefore, $-0.15 \mathrm{~V}$ and $60 \mathrm{~ms}$ were selected as the oxide reduction potential E4 and its duration respectively.

\section{System suitability and sample analysis}

Under the optimized conditions, following the procedure of quantitative method stipulated by European Pharmacopoeia 4.5 07/2003:0331 method, the system suitability of our method was investigated.

According to European Pharmacopoeia 4 01/2002: 1351 method, the minimum ratio of peak-to-valley $H_{\mathrm{p}} / H_{\mathrm{v}}$ should be equal to 2.0 , where $H_{\mathrm{p}}$ is the peak height of gentamicin $\mathrm{C}_{2 \mathrm{a}}, H_{\mathrm{v}}$ is the height above the 
baseline of the lowest point of the curve separating this peak from the peak due to gentamicin $\mathrm{C}_{2}$. By injecting $20 \mu \mathrm{L}$ of reference solution a into chromatography system, a chromatogram was got and then the ratio of peak-to-valley $H_{\mathrm{p}} / H_{\mathrm{v}}$ was calculated. In our case, the ratio of peak-to-valley $H_{\mathrm{p}} / H_{\mathrm{v}}$ was equal to 3.7 , which is greater than 2, therefore the present method could fully meet the requirements of European Pharmacopoeia 4 01/2002:1351 method.

Under the optimized experimental conditions, some replicate injection determinations of reference solution a were done in successive several days and the overlay chromatograms of nine are shown in Figure 5. The RSD data of retention time and peak area for the five gentamicin components in the nine successive determinations are in the range of $0.52 \%-0.91 \%$ and $1.7 \%-$ $3.7 \%$ respectively (Table 1 ). The linearity and sensitivity of our method were also investigated and the results are shown in Table 2. From this table, it can be found that there is a linear correlation between peak area and concentration over concentration change 40 times for the four gentamicin components $\left(\mathrm{C}_{1}, \mathrm{C}_{1 \mathrm{a}}, \mathrm{C}_{2}\right.$ and $\left.\mathrm{C}_{2 \mathrm{a}}\right)$

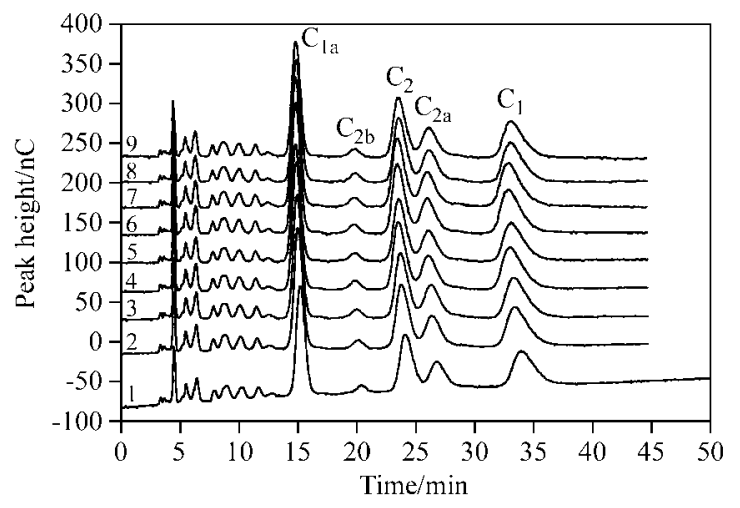

Figure 5 Chromatograms for the reproducibility test of the nine successive determinations.

Table 1 Reproducibility of the retention time and peak area of five gentamicin components in nine replicate injections

\begin{tabular}{lccccc}
\hline Component & $\mathrm{C}_{1 \mathrm{a}}$ & $\mathrm{C}_{2 \mathrm{~b}}$ & $\mathrm{C}_{2}$ & $\mathrm{C}_{2 \mathrm{a}}$ & $\mathrm{C}_{1}$ \\
\hline RSD for retention time/\% & 0.60 & 0.91 & 0.81 & 0.80 & 0.52 \\
RSD for peak area/\% & 1.8 & 1.7 & 3.5 & 3.7 & 2.5 \\
\hline
\end{tabular}

Table 2 Detection limit and linearity

\begin{tabular}{cccc}
\hline Analyte & $\begin{array}{c}\text { Detection limit } \\
\left(\mu \mathrm{g} \bullet \mathrm{mL}^{-1}\right)\end{array}$ & $\begin{array}{c}\text { Linearity range/ } \\
\left(\mathrm{mg}^{-1} \mathrm{~mL}^{-1}\right)\end{array}$ & $r^{b}$ \\
\hline $\mathrm{C}_{1}$ & 4.7 & $0.033-1.33$ & 0.9996 \\
$\mathrm{C}_{1 \mathrm{a}}$ & 1.5 & $0.041-1.66$ & 0.9999 \\
$\mathrm{C}_{2}$ & 2.7 & $0.033-1.30$ & 0.9955 \\
$\mathrm{C}_{2 \mathrm{a}}$ & 3.3 & $0.018-0.73$ & 0.9965 \\
\hline
\end{tabular}

${ }^{a}$ LOD at a signal-to-noise radio of $3 .^{b} r$ is correlation coefficient.

with a correlation coefficient better than 0.9955 and the detection limits measured as three times of the peak height signal-to-noise ratio for the same four gentamicin components were in the range of $1.5-4.7 \mu \mathrm{g} / \mathrm{mL}$. Because the gentamicin sulphate CRS used was a mixture of $26.5 \% \mathrm{C}_{1}, 33.1 \% \mathrm{C}_{1 \mathrm{a}}, 26.0 \% \mathrm{C}_{2}$ and $14.6 \% \mathrm{C}_{2 \mathrm{a}}$, no data about the content of $\mathrm{C}_{2 b}$ were listed. The detection limits listed in Table 2 were gotten by the chromatogram of dilute solution of gentamicin sulphate CRS and the relative content of every individual component $\left(\mathrm{C}_{1}, \mathrm{C}_{1 \mathrm{a}}, \mathrm{C}_{2}\right.$ or $\left.\mathrm{C}_{2 \mathrm{a}}\right)$ in the mixture, therefore the analytical performance data about $\mathrm{C}_{2 b}$ were not available in Table 2. In addition, when too concentrated solution was applied, the separation resolutions between $\mathrm{C}_{2}$ and $\mathrm{C}_{2 \mathrm{a}}, \mathrm{C}_{2}$ and $\mathrm{C}_{2 \mathrm{~b}}$ became very poor, hence the upper limit of concentration selected was not very high.

Following the European Pharmacopoeia 4.5 07/ 2003:0331 method, our method was also applied to analysis of two real gentamicin samples and the results are shown in Table 3. Figure 6 shows the chromatogram of one of the gentamicin samples. From Table 3, it can be found that our method has a good precision, which can guarantee us to obtain more reliable results.

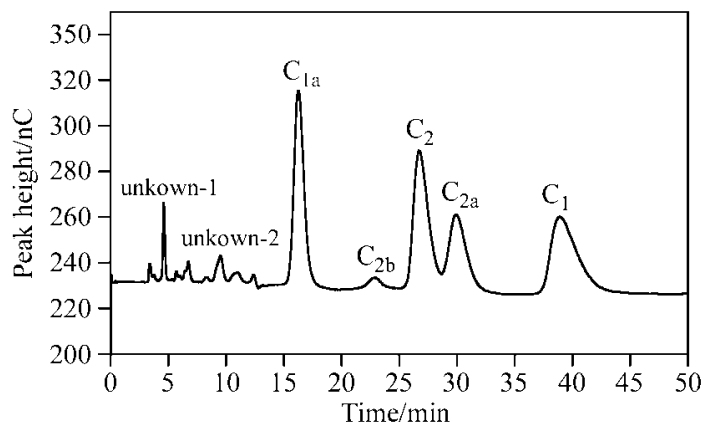

Figure 6 Chromatogram of gentamicin sample.

Table 3 Analytical results of gentamicin samples by normalization

\begin{tabular}{cccccccc}
\hline \multirow{2}{*}{ Sample } & \multicolumn{7}{c}{ Composition of gentamicin samples ${ }^{a} / \%$} \\
\cline { 2 - 8 } & Impurity 1 & Impurity 2 & $\mathrm{C}_{1 \mathrm{a}}$ & $\mathrm{C}_{2 \mathrm{~b}}$ & $\mathrm{C}_{2}$ & $\mathrm{C}_{2 \mathrm{a}}$ & $\mathrm{C}_{1}$ \\
\hline $\mathrm{A} 03001$ & $2.98 \pm 0.15$ & $2.42 \pm 0.18$ & $23.47 \pm 0.38$ & $2.02 \pm 0.14$ & $26.61 \pm 0.10$ & $16.71 \pm 0.60$ & $25.81 \pm 0.78$ \\
$\mathrm{~B} 03006$ & $2.37 \pm 0.08$ & $2.14 \pm 0.14$ & $23.66 \pm 0.41$ & $2.00 \pm 0.13$ & $24.06 \pm 0.30$ & $18.16 \pm 0.52$ & $27.61 \pm 0.71$ \\
\hline
\end{tabular}

${ }^{a}$ Mean and standard deviation for five determinations. 


\section{Conclusion}

In this paper, a quadruple-potential waveform has been successfully extended to the determination of gentamicin components. Instead of a relatively high positive potential, a more negative potential was adopted as a potential for the cleaning of gold working electrode. By using this way, more effective cleaning of the gold electrode was achieved without serious recession of gold working electrode, and therefore a good reproducibility for the determination of gentamicin components was obtained. The analytical method can be applied to the determination of real gentamicin samples.

\section{References}

1 Kabasakalian, P.; Kalliney, S.; Magatti, A. W. Anal. Chem. 1977, 49, 953.

2 Wagman, G.; Marquez, J.; Weinstein, M. J. Chromatogr. 1968, 34, 210.

3 Wilson, W.; Richard, G.; Hughes, D. J. Chromatogr. 1973, $78,442$.

4 Kaine, L.; Wolnik, K. J. Chromatogr. 1994, 674, 255.

5 Seidl, G.; Nerad, H. Chromatographia 1988, 25, 169.

6 Thomas, A.; Tappin, S. J. Chromatogr. 1974, 97, 280.

7 Posyniak, A.; Zmudzki, J.; Niedzielska, J. J. Chromatogr., A 2001, 914, 59.

8 Stead, D. A.; Richards, R. M. E. J. Chromatogr., B 1996, 675, 295.

9 White, L.; Lovering, A.; Reeves, D. Ther. Drug Monit. 1983, $5,123$.

10 Claes, P.; Busson, R.; Vanderhaeghe, H. J. Chromatogr. 1984, 298, 445.

11 Albracht, J.; de Wit, M. J. Chromatogr. 1987, 389, 306.

12 Graham, A.; Speicher, E.; Williamson, B. J. Pharm. Biomed. Anal. 1997, 15, 537.

13 Getek, T.; Vestal, M.; Alexander, T. J. Chromatogr. 1991, $554,191$.

14 Gambardella, P.; Punziano, R.; Gionti, M.; Guadalupi, C.; Mancini, G.; Mangia, A. J. Chromatogr. 1985, 348, 229.

15 Claes, P.; Chaerani, Y.; Vanderhaeghe, H. J. Pharm. Belg. 1985, 40, 95.

16 Anhalt, J.; Sancilio, F.; McCorkle, T. J. Chromatogr. 1978,
153, 445 .

17 Freeman, M.; Hawkins, P.; Loran, J.; Stead, J. J. Liq. Chromatogr. 1979, 2, 1305.

18 Kraisintu, K.; Parfitt, R.; Rowan, M. Int. J. Pharm. 1982, 10, 67.

19 Getek, T.; Haneke, A.; Selzer, G. J. Assoc. Off. Anal. Chem. 1983, 66, 172.

20 Weigand, R.; Coombes, R. J. Chromatogr. 1983, 281, 381.

21 Flurer, C.; Wolnik, K. J. Chromatogr. 1994, 663, 259.

22 Rocklin, R. D.; Clarke, A. P.; Weitzhandler, M. Anal. Chem. 1998, 70, 1496.

23 Clarke, A. P.; Jandik, P.; Rocklin, R. D.; Liu, Y.; Avdalovic, N. Anal. Chem. 1999, 71, 2774.

24 Cheng, J.; Jandik, P.; Avdalovic, N. Anal. Chem. 2003, 75, 572.

25 Jandik, P.; Clarke, A. P.; Rocklin, R. D.; Avdalovic, N.; Andersen, D. C.; Cacia, J. J. Chromatogr., B 1999, 732, 193.

26 Jandik, P.; Cheng, J.; Jensen, D.; Manz, S.; Avdalovic, N. J. Chromatogr., B 2001, 758, 189.

27 Jandik, P.; Cheng, J.; Evrovski, J.; Avdalovic, N. J. Chromatogr., B 2001, 759, 145.

28 Cavalli, S.; Cardellicchio, N. J. Chromatogr., A 1995, 706, 429.

29 Kaiser, K.; Benner, R. Anal. Chem. 2000, 72, 2566.

30 Ding, Y.; Yu, H.; Mou, S. J. Chromatogr., A 2002, 982, 237.

31 Yu, H.; Ding, Y.; Mou, S.; Jandik, P.; Cheng. J. J. Chromatogr., A 2002, 966, 89.

32 Yu, H.; Ding, Y.; Mou, S. Chromatographia 2003, 57, 721.

33 Martens, D. A.; Loeffelmann, K. L. J. Agric. Food Chem. 2003, 51, 6521 .

34 Adams, E.; Roelants, W.; De Paepe, R.; Roets, E.; Hoogmartens, J. J. Pharm. Biomed. Anal. 1998, 18, 689.

35 Jensen, M. B.; Johnson, D. C. Anal. Chem. 1997, 69, 1776.

36 Cai, Y.-Q.; Cheng, J.; Mou, S.-F.; Jandik, P. Pharm. Forum 2004, 30, 2.

37 Burke, L. D.; Buckley, D. T.; Morrissey, J. A. Analyst 1994, 119, 841.

38 Johnson, D. C.; LaCourse, W. R. In Carbohydrate Analysis: High Performance Liquid Chromatography and Capillary Electrophoresis, Ed.: El Rassi, Z., Elesevier Science, Amsterdam, 1994, Chapter 10.

(E0409138 ZHAO, X. J.; ZHENG, G. C.) 